\title{
O caso Londrix: subjetividade, territorialização e política na poesia de Maurício Arruda Mendonça
}

Frederico Fernandes ${ }^{1}$

A série Roteiro da poesia brasileira, lançada pela editora Global, sob direção de Edla van Steen, perfaz um panorama e uma seleção dos principais poetas brasileiros, compreendendo períodos e décadas literárias. Os volumes, divididos em períodos, alcançam até o Modernismo, sendo que os anos subsequentes são todos divididos em decênios, perfazendo um arco de 70 anos da produção poética brasileira. O volume referente aos anos 1990 traz poetas de diferentes idades, sendo a imensa maioria nascidos nas décadas de 1960 e 1970. O que justifica a presença deles num mesmo volume é o fato de que todos os poetas tiveram seus primeiros livros publicados na referida década. Segundo Paulo Ferraz, responsável pela seleção e pelo prefácio do volume em discussão, os anos 1990 compreendem duas fontes de poesia: "uma imediata - o esgotamento dos movimentos literários, em especial o Concretismo e a Poesia Marginal - e outra mediata - a consolidação do Modernismo." Para ele, os autores dessa década não são caudatários de dívidas a movimentos anteriores, nem se identifica neles "qualquer gesto inaugural de uma geração" (Ferraz, 2011, p. 11).

Parece haver nessa perspectiva algo que vem, de certo modo, incomodando a crítica, sobretudo a historiografia literária brasileira. A ausência do "canto uníssono" do fazer poético em torno de um determinado padrão estético e, também, do viés ideológico responsável por congregar os poetas num mesmo "movimento" assinalam uma das principais características da poesia brasileira contemporânea. Os mecanismos de produção da poesia na contemporaneidade desenham-se a partir e, principalmente, da formação de coletivos e da disseminação do texto em performance, que têm como corolário a revalorização da voz. Isso não é um fenômeno apenas identificado em Pindorama. As entrevistas de Enzo Minarelli a Dick Higgins, Nanni Balestrini, Richard Kostelanetz, Charles Amirkhanian, Bernard Heidsieck, Charles Bernstein, entre outros, reunidas em As razãoes da voz, apontam para o culto à performance e para a

\footnotetext{
${ }^{1}$ Doutor em letras e professor da Universidade Estadual de Londrina (UEL), Londrina, PR, Brasil. E-mail: fredericofernandes3@gmail.com
} 
necessidade de organização de coletivos que transcendam as fronteiras nacionais. Tal tendência é também a marca de um modo de operar da produção poética na contemporaneidade, o que justifica a variada escala de estilos e de linguagens presentes no fazer poético nos dias atuais.

Entre os 45 poetas arrolados na seleção feita por Paulo Ferraz, ainda há uma outra semelhança entre eles: com exceção de um ou outro livro, a grande maioria tem sido publicada por editoras independentes, isto é, independentes do mercado, caracterizadas pela circulação restrita e produção centrada na figura do editor, o que as leva, em alguns casos, a serem adjetivadas como "artesanais". Além disso, muitos deles se encontram envolvidos em outros projetos culturais, como tradução, ensaios, edição de revistas, roteiros fílmicos, e possuem títulos de mestre e doutor na área de estudos literários ou filosofia. Tal perfil não é muito diferente de poetas e escritores que tiveram seus lançamentos após a década de 1990. E sua presença já pode ser detectada na década predecessora, configurando um sistema de produção poética sob um regime de redes.

Maurício Arruda Mendonça (1964) e Rodrigo Garcia Lopes (1965) são dois poetas que figuraram na antologia organizada por Ferraz e possuem algo mais em comum: são nascidos e criados na cidade de Londrina, inserem-se numa mesma rede de produção poética e têm seus nomes repercutidos em nível nacional por importantes veículos de circulação, tais como o Suplemento Literário de Minas Gerais (Marques, 2013) e a antologia 101 poetas paranaenses (Demarchi, 2014), entre muitas outras. Ambos os poetas atuam num arco consideravelmente extenso de atividades culturais. São dois poetas, mas também podem ser denominados escritores, tradutores, músicos, pesquisadores de literatura e cultura, editores de revista ou organizadores de livros. São artistas que vivenciam atravessamentos, cujo movimento os leva a superposições entre áreas de conhecimento e papeis culturais. Outro dado importante a ser ressaltado são os produtos gerados por meio da parceria entre os dois. Entre eles, cabe destacar a tradução de Iluminuras, de Arthur Rimbaud (1994), e de Sylvia Plath: poemas (1990); a edição das revistas K'AN, na década de 1980, e Coyote, com 26 números publicados entre 2002 e 2014; além da importante atuação nas programações do Festival Literário de Londrina, o Londrix, desde seu início, em 2004.

Se a seleção de Paulo Ferraz, dos 45 poetas que publicaram nos anos de 1990, permite entrever uma variedade de temas e estilos poéticos, o mesmo 
pode ser identificado em menor escala quando os dois poetas são aproximados. Em que pese o fato de a parceria entre Rodrigo e Maurício estender-se para a composição conjunta, como no lúdico "Trilha da Graciosa descendo a pé, Uma sessão de Haikai" (Mendonça, 2002, p. 45-47), não é perceptível um projeto estético comum entre eles. A poesia sinaliza para uma liberdade do fazer e do expressar, em que a marca coletiva irá se evidenciar nos trabalhos feitos no intuito de também tornar visível a obra de cada um. Por isso, há semelhanças, mas também muitas diferenças na poesia dos dois. E, por haver uma sintonia maior entre a lírica de Maurício Arruda Mendonça e a cidade de Londrina, as discussões ancoram-se, neste artigo, em seus livros de poemas, como forma de compreender melhor a rede Londrix.

O debate sobre a poesia contemporânea, ora proposto, fundamenta-se na observação de um modo peculiar de produção e circulação literária, estando, dessa maneira, atrelado à noção de sistema. Sua fundamentação teórica vale-se, sobretudo, de filósofos que analisam e interpretam a mudança no regime de produção artística da modernidade para a contemporaneidade, tendo as artes plásticas como ponto de partida, mas não se atendo exclusivamente a elas. As vanguardas históricas e a pósvanguarda da segunda metade século $X X$ deixaram uma grande lição sobre dissolução de fronteiras entre literatura e outras artes, em que a performance se tornou uma importante referência para a crítica. A escolha de Anne Cauquelin, Jacques Rancière e Nicolas Bourriaud, por exemplo, para dialogar com a construção da rede Londrix não se configura como uma mera ilação teórica, muito menos intenta mergulhar o leitor numa vazia sofisticação crítica de atualização dos estudos literários. A utilização de tais pensadores permite verificar no campo literário a existência de algo caro à literatura e que tem sido negligenciado pela sua historiografia: a noção de ato. Reconhecê-la implica trazer a voz, a presença e os modos de afetividade operados ao interno e ao externo do texto poético. Por isso, tais filósofos foram nominados neste artigo como forma de reconhecimento de sua contribuição para a compreensão de um sistema de produção das artes na contemporaneidade, permitindo a articulação de um pensamento crítico no qual os poemas de Maurício Arruda Mendonça acoplam-se, como será demonstrado em várias passagens adiante.

Anne Cauquelin, em seu livro sobre arte contemporânea, postula que o papel do artista moderno se diferencia do contemporâneo porque, 
enquanto o primeiro encontra-se preso ao mercado, o segundo constitui-se mediante um regime de rede. Para explicar tal regime, ela cita o linguista Roman Jakobson, no sentido de assinalar uma correspondência da função do artista à função embreante.

O termo "embreante" designa, em linguística, unidades que têm dupla função e duplo regime, que remetem ao enunciado (a mensagem, recebida no presente) e ao enunciador que a anunciou (anteriormente). Os pronomes pessoais são considerados embreantes, pois ocupam um lugar determinado no enunciado, onde são tomados como elementos do código, além de manterem uma relação existencial com um elemento extralinguístico: $o$ de fazer ato $d a$ palavra (Jakobson apud Cauquelin, 2005, p. 87-88, grifo nosso).

Ao fazer o ato da palavra, o poeta contemporâneo desempenha um papel semelhante ao do artista descrito por Cauquelin: ele assumirá duplamente a posição de enunciador (a subjetivação do poema) e de enunciado (a posição de sua obra), numa relação anafórica. No caso, o poeta é tanto o poema per se, no sentido em que por meio do código estético configura-se seu processo de subjetivação, como se duplica ao transformar a obra em ato. O fato de a obra (mensagem enviada) voltar a seu antigo autor (no aspecto da singularidade de quem a anuncia) denuncia o movimento anafórico, fazendo surgir elementos do passado na atualidade. Aí reside o ato. Entender a produção poética nessa perspectiva implica adentrar os meandros do implexo sistema literário brasileiro contemporâneo e alcançar uma compreensão de como a produção poética se realiza em seu meio.

Perscrutar o ato da palavra corresponde a compreender os atores sociais da produção literária e os vários papeis que desempenham. Assim, é na análise do ato que emergem a crítica às regras do campo do fazer literário e também as estratégias e investidas de seus agentes para mantê-las ou modificá-las. O ato tem a ver diretamente com a arte em seu mecanismo de produção, compreende um locus de atuação e interação, o qual também terá seus reflexos na representação espacial do poema. Insinua hierarquias e tradições que atravessam a arte ou formas de relacionamento de pessoas com instituições, as quais podem tanto ser combatidas como corroboradas por gerações distintas. Incita o associativismo por meio de desenvolvimento de projetos comuns. Tensiona os limites da rede, expandindo ou encolhendo sua capacidade de penetração social e midiática. Subvenciona a migração e a 
simultaneidade do corpo da poesia: a permanência do texto impresso aliada à circulação digital e/ou performática.

Desse modo, o ato da palavra acautela a mudança necessária à sobrevivência da arte. Sua análise demanda a reunião de diferentes tipos de fontes - como poemas, entrevistas, críticas a respeito -, além de produtos culturais derivados da ação dos agentes estudados - como canções, vídeos e edições de revistas, festivais. A partir da análise do ato da palavra, depreende-se como Maurício Arruda Mendonça e os demais poetas da rede Londrix "marcaram época", segundo a expressão de Bourdieu (1996, p. 181).

\section{Território Londrix}

Por mais que os livros de poesia de Maurício Arruda Mendonça sejam aqui interpretados a partir da ideia de um regime das redes - isto é, sendo distinguidos pela descentralização e o atravessamento e, assim, constituindo-se com base numa dinamicidade e transitoriedade -, faz-se presente uma ancoragem territorial em sua lírica. O território, nesse caso, caracteriza-se como o espaço uterino da rede, no qual ela se desenvolve e firma sua existência, mas também é aquele que, ao formá-la, é pela rede transformado. Por isso, encontra-se inserido em sua própria dinâmica.

A cidade de Londrina deixa de ser a paisagem passiva a ser cantada ou imortalizada para se tornar o proscênio onde a rede encena sua tessitura. Em entrevista a Marco Vasques, numa coletânea voltada exclusivamente a poetas paranaenses, Maurício Arruda Mendonça assim se manifesta sobre a sua cidade natal:

Qual cidade que você conhece cresceu como Londrina de 1934 a 1984? Veja, a cidade dos meus contos tem apenas 75 anos. Não creio que haja outra cidade que fez um experimento de tempo tão radical. Talvez Brasília, mas Brasília já nasceu como marco da arquitetura moderna, né? Londrina pulverizou o tempo. Muita coisa aconteceu em pouco tempo. [...] Estou falando de uma cidade que nasceu sob o mito do Eldorado, que se construiu com esse imaginário da fertilidade da terra vermelha, resultado do maior derramamento da lava basáltica do planeta. Então, sob esse clima, há um paroxismo de paixões, o sexo explode, o desrespeito às regras, à lei e às convenções éticas e morais são desejados e aceitos. Some-se a isso que Londrina foi "a cidade mais rápida do Brasil", como disse Paulo Leminski (Vasques, 2010, p. 235). 
A pergunta referia-se diretamente ao livro de contos Londrinenses, uma reunião de histórias publicadas originalmente no jornal Folha Norte que ficcionalizam e apresentam casos particulares vinculados à identidade de Londrina. Tanto Maurício Arruda Mendonça como Rodrigo Garcia Lopes valem-se desse universo de acontecimentos peculiares da cidade do norte paranaense. Rodrigo terá a cidade como fundo em seu primeiro romance, $O$ Trovador, ambientado numa Londrina dos anos 1930. A ficção abre uma possibilidade de diálogo mais direto com a cidade, em que suas paisagens, acontecimentos e personagens fazem-se evidentes. Na lírica, essa relação acontece de modo mais velado, em que a observação do espaço urbano, paisagens sazonais e comportamentos diluem-se numa intensificação da palavra, fazendo com que o local transforme-se em global.

Nessa linha de raciocínio, as referências diretas a Londrina nos poemas de Maurício Arruda Mendonça são raras e pontuais. No entanto, em Eu caminhava assim tão distraído (1997), seu primeiro livro, é possível depreender uma associação mais direta com a cidade em dois poemas: "Londrix" e "Lago artificial". O primeiro viria a batizar o nome do principal festival literário de Londrina, que remonta a 2004, sete anos após a publicação do livro. O segundo sugere uma inevitável associação com o conjunto de lagos artificiais, cartão postal da cidade, chamado Igapó.

Já desponta no poema "Londrix" o lirismo contemplativo, em que a imersão outonal do sujeito lírico singulariza estados de espírito como a separação, a reconciliação e a contemplação da simplicidade da vida, como se pode notar nos excertos abaixo:

quando é outono

os galhos temem

que folhas

os deixem $[\ldots]$

agora

batendo na vidraça

"quer entrar?"

os galhos perdoam

o vento $[\ldots]$

felicidade:

dizer coisas

tão simples 
como:

"galhos"

ou

"você vai

sair sem

o casaco?" (Mendonça, 1997, p. 15-16)

É nítida aqui a ressonância da poesia de Nenpuku Sato (1898-1979), cujos haicais foram traduzidos por Maurício Arruda Mendonça, na maneira como o lírico busca absorver da contemplação da natureza um ensinamento de vida. De Trilha forrada de folhas, destaca-se:

Palavra de consolo

Inda mais triste

O vento de outono (Sato, 1999, p. 91)

O tom melancólico reforçado pela assonância de vogais fechadas (outono, vento, consolo) e a natureza como expressão do espírito humano são marcas do lirismo encontrado na tradução de Sato que, mutatis mutandis, intensificam-se na poesia do próprio tradutor, principalmente nos livros publicados posteriormente: A sombra de um sorriso (2002a) e Epigrafias (2002b). Em poemas como "Manhã fria", essa influência salta à vista, devido à inquietação com o tempo e a superação da morte, que se realizam na contemplação da vida de uma borboleta:

Manhã fria

você está viva

velha borboleta? (Mendonça, 2002a, p. 27)

Em "Invernescer", a linguagem dá sinais de certa elasticidade em relação à forma rígida do haicai, sem abandonar de vez a trilha aberta pelo mestre japonês. $\mathrm{O}$ tema repousa sobre as tensões entre o dizer e o contemplar, em que o inefável alia-se ao mesmo tempo ao silêncio e à estese:

Na manhã nublada, sem dizer uma pa-

lavra, olho pela janela interminavelmente

o vento, o jardim (Mendonça, 2002a, p. 44).

A ligação com Nenpuku Sato não é apenas o reflexo da herança de uma geração, que se viabiliza por meio da replicação do tema, a busca da simplicidade e do culto a um gênero específico, no caso a poesia minimalista - algo também advindo da influência de Paulo Leminski, sobretudo no caso de Garcia Lopes. Ao ter sido traduzido e divulgado 
por Arruda Mendonça, Nenpuku transforma-se numa espécie de paideuma poundiano, que norteará o processo de criação. Há aqui marcas significativas da produção em regime de rede, conforme a define Cauquelin: o contato do eu empírico com Sato transcende o eu lírico do poema em análise, alçando ambos para a instância simbólica legitimadora da criação.

O ato da palavra, nesse caso, não é o exercício da influência de um poeta consolidado sobre outro de uma geração mais jovem. Ele é o posicionamento de um coletivo de poetas e artistas, constituidores de uma rede, pautado em valores de produção que legitimam alguns princípios estéticos. Como desdobramento, serão os agentes dessa rede que também promoverão outros poetas, alguns até predecessores, sob forma de diversos produtos culturais: peça de teatro, recitais, antologias, shows, traduções (como no caso de Nenpuku Sato, Arthur Rimbaud, Sylvia Plath), entre outros.

Uma das marcas mais fortes dos cruzamentos entre o eu empírico e o eu lírico no poema em tela será a carga semântica que carrega o título do poema em questão: "Londrix". Em "Relíquia íntima e perecível", Eduardo Sterzi já alerta para uma bivocalidade na poesia de Arruda Mendonça. Segundo ele, sua lírica é atravessada por um elemento relativamente autônomo "que se impõe por sua materialidade e estranheza sobre os traços de humanidade presentes no poema" (Sterzi, 2002, p. 92). O corolário disso é que, na opinião de Sterzi, Maurício Arruda Mendonça "fracassa em seu embate poético contra o tempo e a morte por deixar seu discurso envolver-se pelas autodeterminações involuntárias" (Sterzi, 2002, p. 97). Ou seja, trata-se do cotidiano vivenciado, trazido por um eu-empírico, que atravessa e rebate o espírito lírico. Mas o que Sterzi analisa como negativo na poética de Arruda Mendonça pode revelar-se um grande trunfo. O que aqui se defende é que as autodeterminações podem não ser involuntárias e figuram como uma maneira de deixar uma marca autoral, baseada num sentimento de pertencimento, de um estar-sendo num tempo e espaço e que, nesse sentido, avançam para uma semântica confessional de uma territorialidade. Examinando mais de perto a crítica à "automação", pela qual Sterzi observa a "submissão do poeta ao poema", nota-se que ela se revela mais como uma diç̧ão local envolta pela cotidianidade ou a vida vivida no território, de onde o eu empírico soprará a lírica. Isso talvez não esteja tão evidente nos quatro poemas que foram pautados para a crítica 
de Sterzi, mas certamente se fazem com mais intensidade nos poemas aqui em perspectiva. ${ }^{2}$

Assim, o exame da bivocalidade na poesia de Arruda Mendonça porá em evidência as formas de conexão fundamentadoras da produção lírica, já que na voz do eu empírico transparece o modo como os poetas de um mesmo grupo afetam-se mutuamente. A afetividade é entendida aqui nos moldes como Luciana di Leone (2014) interpreta a poesia contemporânea brasileira, sobretudo a da cena carioca e a portenha, da Argentina. Segundo ela, o afeto é compreendido a partir das estratégias de (auto)disseminação da poesia, por meio de uma investigação das práticas do ler, escrever e editar, bem como pela questão do relacional, isto é, pelos modos de "viver junto" e a organização de coletivos artísticos. A chamada revitalização da poesia brasileira dada a partir da década de 1990 é marcadamente afetiva, caracterizando-se, ainda de acordo com Leone, pela "ausência de projeto e de programa definido" e pela "pluralidade ou diversidade de vozes e dicções" (2014).

Esse é um dos princípios caracterizadores do Londrix enquanto um coletivo que contamina a poesia. Sua semântica, de modo inequívoco, remete a Londrina, porém não é a cidade em sua constituição históricourbana, mas a figuração de um território cuja existência denuncia a articulação de artistas de várias áreas que de alguma maneira se ligam, trocando leituras. O poeta, jornalista e cronista Nelson Capucho (2016), assim se manifesta sobre a origem do termo Londrix:

Eu criei a palavra nos anos 80 (muito provavelmente em 1984, quando lancei o livro Sundae Cogumelo). O escritor Jair Ferreira dos Santos (que é de Cornélio Procópio, mas mora no Rio há muitos anos) havia lançado um livro de contos e numa das histórias, ele mencionava uma cidade fictícia chamada Lond, obviamente uma referência a Londrina. Eu fiquei então pensando num apelido pra nossa cidade que fosse simpático e moderno ao mesmo tempo. Havia um grafite que se tornou popular na época que dizia: "Mandril, Mandrax, Mandrix"... Era praticamente um poema concreto. (Mandrix era um alucinógeno, a metaqualona). Então juntei as duas ideias e formei Londrix, que passei a usar em cartas para amigos. Enviei um livro meu pro Rodrigo Garcia Lopes, que estava

\footnotetext{
2 Entre os poemas constam: "Essa Alegria", publicado em A sombra de um sorriso (2002a), "Ver Claramente", publicado em Epigarafias (2002b) e "Dia límpido" e "Tempo que foge do olhar", ainda não publicados em livro.
} 
passando uns tempos em Londres, e na dedicatória fiz um "plágio" do grafite: "Londres, Londrina, Londrix". O engraçado é que o Rodrigo nunca me falou nada sobre o livro e eu nunca perguntei se ele recebeu [risos]. O escritor Wilson Bueno, de Curitiba, me pediu um pequeno texto para um dos primeiros números do jornal literário "Nicolau" e eu botei o título de "Londrix". Amigos de Curitiba acharam bem legal. Outras pessoas do meio adotaram a palavra aqui e lá. Em 1999, decidi mudar o nome de uma pequena empresa de comunicação que eu tinha (se chamava Canto da Terra) e botei Londrix. Logo em seguida fizemos o site com este nome. Alguns anos depois, a Christine Vianna lançou o Festival Literário de Londrina e me procurou pra saber se poderia usar o nome da empresa como uma segunda denominação do evento. Eu achei superlegal! O nome deu sorte, já que o Festival resiste até hoje (vai pra $12^{a}$ edição) e a minha pequena empresa já tem 16 anos. A história é esta. Espero que tenha ajudado (Capucho, 2016).

Londrix traz em sua semântica um tom subversivo, marginal e underground. O nome é um modo de ser, uma identidade e passa a agregar jovens e antigos poetas, músicos, produtores culturais, artistas plásticos, atores e fotógrafos em torno dele. Londrix é marca de um coletivo que se caracteriza pelos trânsitos artísticos, em que seus membros assumem múltiplos papéis. Torna-se um festival, cuja importância é a operacionalização da rede, abrindo-a para o contato com artistas de outros estados, sem deixar de promover poetas locais. A arte Londrix é temperada com uma certa dose de rebeldia, de uma atitude antiburguesa e, portanto, anti-individualista, sem abrir mão da subjetivação. Cabem nela desde a denúncia social mais direta ao lirismo romântico; o erotismo mítico e libertário; a consciência do amadurecimento e a arrogância jovial; o intelectualismo de fundo acadêmico e a apologia à velocidade das ideias. Tal panorama é obtido por meio do contato com as antologias.

A antologização vem se configurando cada vez mais como uma prática comum de disseminação poética na literatura brasileira. A poeta, produtora cultural e editora Christine Vianna tem protagonizado um papel importante na organização de antologias junto ao coletivo Londrix. O objetivo principal é divulgar escritores locais em escolas. Sendo assim, a recém-lançada publicação Um dedo de prosa (2016) e a Antologia de poetas londrinenes 12 (2000) tendem a servir também como material de apoio para um projeto que visa aproximar escritores locais de escolas de ensino fundamental e médio, principalmente por meio da 
performance poética. As antologias não se caracterizam por uma estética dominante ou regras de produção. Existem nelas vozes em diversas dicções poéticas, reproduzindo em menor escala aquilo que Paulo Ferraz detecta em sua antologia da geração 1990: “o sincretismo, o ecletismo e a mestiçagem" (Ferraz, 2011, p. 15).

Práticas de edição, organização e curadoria acabam se tornando comuns entre os membros do grupo. Ainda nesse cenário, ocupam papel de destaque a revista Coyote e as editoras KAN, do designer gráfico, jornalista, crítico e poeta, Marcos Losnak, a Atrito Art de Christine Vianna, e, mais recentemente, a Madrepérola, do designer Rafael Rodrigues. Essas publicações, juntamente com o Festival Literário de Londrina - Londrix, protagonizam importantes papeis na cena literária, constituindo-se, claramente, como um regime de redes da arte e, principalmente, da poesia.

A rede, retomando Anne Cauquelin (2005), é uma trama de complexas conexões pautadas pela ordem das trocas, dos trânsitos e das relações. A sua dinâmica implica a troca entre agentes de um mesmo grupo e também com grupos de outras localidades. O regime de redes articula-se em meio a uma ordem, em que, devido ao grau de abertura, conexão e trânsito com outras redes, acaba por criar uma principal, isto é, de primeira grandeza, e outras menores consideradas satélites. $\mathrm{O}$ que estabelece tal ordem são os produtos comunicados, sendo que "a noção do 'sujeito' comunicante apaga-se em favor de uma produção global de comunicações" (Cauquelin, 2005, p. 60). No caso da revista Coyote, por exemplo, ela apresenta uma diagramação bastante original, crivada por imagens artísticas e com uma mancha que valoriza o texto poético e a imagem. Seu conteúdo gira em torno de traduções originais de poetas, o que reforça a transitividade entre línguas, países e culturas, além de ensaios, contos, excertos narrativos e, principalmente, poesia brasileira. Do ponto de vista editorial, ela é de responsabilidade de jornalistas e poetas também vinculados à rede Londrix (Ademir Assunção, Marcos Losnak e Rodrigo Garcia Lopes), mas seu conselho editorial é composto exclusivamente por poetas, de fora do país ou reconhecidos nacionalmente, ${ }^{3}$ que demonstram a capacidade de alcance da rede. A

${ }^{3}$ O conselho editorial da Coyote é composto pelos escritores e poetas Nelson de Oliveira, Douglas Diegues, Juvenal Pereira e Maurício Arruda Mendonça, além do poeta e tradutor norte-americano Chris Daniels, de Berkeley, EUA. 
profusão de nomes literários e de críticos, associada à estética da diagramação, confere a cada volume a sensação de contato com uma obra de arte única e deixa manifesto o desejo de produzir uma marca. Uma marca no sentido em que Pierre Bourdieu (1996) a entenderá, ou seja, a revista torna-se um objeto simbólico envolto pela raridade da assinatura, sem a presença física do sujeito empírico que de fato a assinaria. Em outras palavras, a revista acaba por criar uma ligação simbólica a partir da publicação de textos de nomes como Chacal, Walt Whitman, Jorge Luis Borges, Paul Celan, Jacques Roubaud, Po-Chü I, entre muitos outros, juntamente com os poetas da rede Londrix. Além disso, poetas de redes de outras cidades e também iniciantes acabam se fazendo presentes, $\mathrm{o}$ que determina a dinâmica de conexões. $\mathrm{O}$ uso da marca nesses moldes tem como corolário um efeito de oxigenação na arte literária, promovendo jovens talentos sem o comprometimento estético e de pertencimento comum a movimentos, períodos e estilos recorrentes na história literária brasileira anterior aos anos de 1970.

Londrix, portanto, define-se como um coletivo de singularidades, pautado num forte sistema de comunicação. As antologias, a revista bem editada, os livros de editoras locais, com forte apelo artístico, colocam os produtos da rede num nível elevado e de reconhecida qualidade. A poesia deixa de ser apenas conteúdo para se tornar também um continente, ou seja, o espaço que, per se, colocará o texto em situação de obra.

É dentro de tal singularidade em meio à diversidade coletiva que o poema "Londrix", de Maurício Arruda Mendonça, faz-se lido. A lírica, nesse poema, traz como pulsão mais evidente o atingimento da felicidade por meio da vida simples. Há nele valores que fazem remissão ao Classicismo, na medida em que guia seu receptor para uma verdade de mundo, porém numa linguagem sem a peculiar uniformidade métrica e rítmica. Em sua maioria, os versos são compostos por uma ou duas palavras, criando um efeito de ritmo quebrado, o que causa uma valorização da ideia a ser transmitida em detrimento da sonoridade. $\mathrm{O}$ desalinhamento da estrutura métrica e sintática, característico do enjambement, reforça a ênfase na estrutura intelectual do poema e no arranjo das palavras alinhado ao plano de conteúdo. O poema é todo crivado por expressões de sensações e sentimentos, ligadas à observação das coisas simples do mundo, como em: "olhar o céu/ e dizer/ como os romanos // 'as nuvens são escamas'". 
Um conceito de território irrompe, então, como uma espacialidade determinada pela palavra. Suas fronteiras são definidas pelo discurso e, por isso, são instáveis. O título, nessa perspectiva, catalisa um processo de subjetivação, por meio do qual o território Londrix se erige em uma de suas modalidades representativas. Ao ser nomeada, a palavra Londrix insinuase como um locus, não propriamente físico, no qual um sistema de representação do mundo, a simplicidade da vida, a consciência da fugacidade do tempo e o contato com a felicidade constituem um modus vivendi. O sujeito empírico deixa sua marca indelével ao nomeá-lo e realiza, desse modo, a partilha da identidade. Ou como bem observou Jacques Rancière a respeito do regime das artes no mundo contemporâneo: "As práticas artísticas são 'maneiras de fazer' que intervêm na distribuição geral das maneiras de fazer e nas relações que estas estabelecem com as maneiras de ser e as formas de visibilidade" (2010, p. 14).

O efeito da bivocalidade será a alternância dos corpos na arte: um corpo lírico que se engendra pela organicidade sígnica do poema; e um corpo comunitário, movimento autêntico de um fazer poético em meio a uma produção coletiva que anseia ser visto. Em última instância, as vozes denunciam que o ato estético, em decorrência da partilha da identidade que realiza e o regime de redes ao qual está atrelado, não deixa de se transformar em uma atitude política. O poema serve, desse modo, ao ato da palavra. Ele é a própria materialidade de um modo de articulação entre as maneiras de fazer, desdobradas em ações práticas que o tornarão visível à medida que institui modos de conceituação. Em última instância, a poesia lato sensu é e será o pivô do regime de produção da rede Londrix.

Um processo semelhante pode ser identificado no poema "Lago artificial", em que o tom lírico da fugacidade do tempo e a relação do estado de espírito com a natureza fazem-se presentes. O lago pode ser tomado como uma metonímia do processo histórico de Londrina, aludindo ao desenvolvimento acelerado e peculiar, conforme asseverou Arruda Mendonça em entrevista dada a Marco Vasques (2010). Há no poema em tela uma dicção prosaica, marcada pelo desalinhamento métrico e sintático, em que, como no poema anterior, aqui também é notado o emprego recorrente do enjambement, que confere uma continuidade e justaposição de imagens e raciocínios.

o lago perpetua suas proezas épicas

feito nossos instantes fizessem parte de um processo comum, essas águas 
e essas lágrimas de lodo ou mesmo

idéias soluçando soluções propícias:

um redescobrir das forças que integram

a vontade de olhos que vêem mais fundo

um bulevar vazio, um cognac, esta sutileza

quem sabe fosse música fugitiva

esses sopros do vento

quem sabe fossem harpas noturnas

a dor dos elementos (Mendonça, 1997, p. 20).

Por meio dessa técnica de composição, o "eu" vai se imiscuir à paisagem, criando um efeito de subjetivação e, ao mesmo tempo, de desrealização, no sentido em que a palavra poética arvora-se como exclusiva mediadora da realidade. O lírico, não de modo despretensioso, chama logo de início a atenção para o fato de que "o lago perpetua suas proezas épicas". Estaria ele denunciando a automação de um projeto desenvolvimentista? Ou, não de forma contraditória, denuncia os esvaziamentos épicos para elucidar a vida vivida em "um processo comum"? Uma das formas de se ouvir os sopros do vento é recuperar um sentido para o passado. Aceitar tal desafio na leitura do poema implicaria contrapor o moto-contínuo desenvolvimentista com o argumento humanista que denuncia a "dor dos elementos".

Lido nessa perspectiva, o poema "Lago artificial" não deixa de ser, a seu modo, reminiscência da própria artificialidade do discurso desenvolvimentista, substrato do crescimento da cidade de Londrina e outras cidades do norte do Paraná (como Maringá). Seu traçado original sobre a mítica rota de Peabiru, feito por engenheiros da Companhia de Terras do Norte do Paraná, fomentou o imaginário de um novo Eldorado. Envolta por esta ideologia, irromperam monumentos e grandes obras arquitetônicas que corroboravam a ideia do progresso e do viver bem. Fundada em 1934, Londrina já apresentava nos anos 1970 uma população urbana que era mais que o dobro da rural (Ferreira e Simon, 1998). A cidade durante os primeiros 40 anos de sua existência seria palco de grandes investimentos urbanísticos, como a construção do Lago Igapó, entre 1957-59, com posterior projeto paisagístico de Roberto Burle Marx; a arquitetura da nova rodoviária, em formato de uma nave espacial (projetada por Oscar Niemeyer nos anos 1970); e os prédios em concreto armado feitos por Vilanova Artigas nos anos 1950. Tais obras não apenas 
colocavam Londrina em sintonia com o espírito de modernidade e progresso brasileiros buscados com a expansão econômica para o Oeste na segunda metade do século XX. Mas, sob as "asas do progresso", eram, também, silenciadas a desigualdade social e sua filha dileta, a violência urbana.

O projeto do Lago Igapó, feito para comemoração do jubileu de Prata, erigia-se, conforme asseveram os historiadores Ferreira e Simon (1988), contra um antigo loteamento clandestino do Parque Guanabara, marcando uma evidente posição entre os "novos-ricos" e as "classes desclassificadas que enfeiavam a cidade". Nas palavras deles:

De fato, uma margem do lago embelezou-se com o clube e suntuosas residências. Do outro, barracos e outras construções estendiam o Parque Guanabara. Assim, uns dez anos depois, o projeto CURA aconselha sua "reurbanização", ou "desfavelamento" (Ferreira e Simon, 1988, p. 352).

Tanto o poema como a lição histórica, que parece por ele ser desperta, expressam que, sob a beleza do lago, encontram-se "lágrimas de lodo ou mesmo/ideias soluçando soluções propícias". Mas logo o que parece ser uma convergência entre a história e a literatura dá vazão a uma força lírica que não é sentida como um movimento idêntico de olhar e narrar o passado. O poema "Lago artificial" transcende o diálogo com a temporalidade que denuncia, conferindo à grandeza "épica" do progresso uma carga semântica capaz de conectar o presente a um porvir. Transcende porque a relação da poesia - e também do poema em debate - com o tempo é bastante diferente da história. É diferente não apenas porque a assonância dos versos acima tenciona na palavra uma vocação simbolista, mas também porque enquanto o olhar do historiador fixa-se na temporalidade e no contexto, o olhar do poeta está voltado para o evento. Na medida em que o primeiro reforça a ruptura passado/presente, ao tratar especificamente do passado, o lírico intensifica o acontecimento, criando um efeito de suspensão cronológica pela ênfase no presente. É da copiosa obra de Alain Badiou, Logic of worlds, que o conceito de evento será, ad hoc, pinçado. Em suas palavras:

o evento não pode ser o que está "entre" um passado e um futuro, entre o fim de um mundo e o começo de outro. Pelo contrário, é intromissão e conexão: realiza o contínuo indivisível da virtualidade. [...] O evento fala sobre a existência do tempo, ou o tempo como contínua e eterna instância do existir; ele não realiza 
qualquer divisão no tempo, não insere qualquer intervalo vazio entre duas temporalidades. $\mathrm{O}$ "evento" refuta o presente como passagem e separação (Badiou, 2009, p. 382-383, tradução nossa).

Por isso, o poema "Lago Artificial" vem como uma experiência do contato com o mundo e surte efeito enquanto o desvelamento de uma verdade. Ele se realiza poíesis na plenitude, isto é, o poema impõe-se como um movimento de "levar-a-ser" sobre o tempo, num grau de discursividade muito diverso do que almeja o historiador. A poesia, operando ao interno da própria linguagem, transpõe o "lago" da sua condição de fato/fenômeno particular para o geral, subsumindo-o.

Nesse movimento, a poesia não é regida pelo diapasão do tempo, foge à ordem cronológica e não deixa rastros de uma ruptura passado versus presente. Sua temporalidade é um "estar-sendo", o que gera, com isso, o seguinte paradoxo: o presente é toda temporalidade que a experiência poética é capaz de comunicar e, ao mesmo tempo, inexiste na poesia. A temporalidade poética torna-se, desse modo, uma forma de conexão e ao mesmo tempo intromissão, como tão bem observou Badiou (2009).

Se a poesia realiza a suspensão do tempo, como perceber nela um ato? Recapitulando: no poema anterior, "Londrix", esse ato constituía-se mediante a alternância de vozes em que o efeito estético atrela-se ao regime de produção artística, ocasionando a partilha da identidade. Sendo um movimento exterior ao poema, sem deixar de manter uma profunda ligação com sua linguagem estética, o ato deflagra a condição embreante. Assim, o poema atrela-se a um duplo regime comunicacional: o do enunciado voltado para a mensagem, e o de seu enunciador como um elemento extralinguístico do texto.

Já no poema "Lago Artificial", conforme apontado, ocorre uma operação semelhante. Nele, o sujeito lírico cria uma ruptura com a temporalidade histórica, preservando a experiência de mundo. Isso transpõe o poema para a condição de evento. Um evento é uma forma de conexão e intromissão latente e, portanto, a partilha da identidade realizada pelo enunciador é transcendida pelo potencial duradouro de identidade(s) que a lírica poderá evocar. Aí encontra-se a principal diferença entre os dois poemas, mas tanto em um como noutro podem ser sentidas as marcas indeléveis de uma bivocalidade. O ato da palavra será viabilizado, então, mediante a partilha da identidade, presente tanto no campo semântico da palavra do poema como nas relações de subjetivação do sujeito comunicante. 
O poema em tela define-se, nessa ótica, como uma materialidade produzida e circulada num espaço de relações humanas que sugere possibilidades de trocas. Tal definição ajusta-se também aos demais poemas de Maurício Arruda Mendonça, já que se vislumbra neles a transformação das circunstâncias dadas pelo presente num mundo sensível e conceitual, fazendo do contexto da vida uma experiência duradoura.

Tal esquema explica muito o funcionamento de coletivos na poesia contemporânea, em que a união entre poetas e seus receptores não é mediada por um conjunto de regras estéticas. Sequer identifica-se um substrato conceitual limitador da produção literária como em movimentos e períodos literários. A partilha pressupõe uma intersubjetividade no sentido em que o poeta, por meio de seus papéis e produtos, valoriza como tema central o "estar-juntos". O território é assim um espaço de múltiplas subjetividades e expressões, apropriações e afetos, afiançado pela criatividade ilimitada que, não raramente, tende a transpor o texto impresso para a performance.

Um exemplo disso é o que acontece com o poema que dá título ao livro, "Eu caminhava assim tão distraído", musicado e cantado por Bernardo Pellegrini. Ao criar um introito para a canção, com versos do beatnik Lawrence Ferlinghetti, Pelegrini insere mudanças no poema, assinalando não apenas um sentimento de ligação a Maurício Arruda Mendonça, mas alavancando-o para outras possibilidades de significação, situando-o no estatuto do agir. Cabe aqui o olhar atento de Nicolas Bourriaud sobre os mecanismos relacionais da arte no mundo contemporâneo. Segundo ele, "a subjetividade só pode ser definida pela presença de uma outra subjetividade; ela só constitui um 'território' a partir de outros territórios que encontra" (Bourriaud, 2009, p. 127).

É no desdobramento desse paradigma de construção artística que se observa uma multiterritorialização da poesia dos anos de 1970 para cá no cenário brasileiro. A ideia de uma total liberdade de criação veio acompanhada de variadas autoidentificações artísticas, o que, em certa medida, imputou à crítica a dificuldade para o delineamento de uma arte própria tanto quanto do sujeito responsável por sua criação. A marca contemporânea é aquela que leva os sujeitos a transitarem por diferentes campos de linguagem e é nessa pulsão por uma multiplicidade que se distingue uma das mais ricas características da poesia hoje em dia: a liberdade do fazer. 


\section{Referências}

BADIOU, Alain (2009). Logic of worlds: being and event II. Tradução de Alberto Toscano. Nova York: Continuum.

BOURDIEU, Pierre (1996). As regras da arte: gênese e estrutura do campo literário. Tradução de Maria Lucia Machado. São Paulo: Companhia das Letras.

BOURRIAUD, Nicolas (2009). Estética relacional. Tradução de Denise Bottmann. São Paulo: Martins Fontes.

CAPUCHO, Nelson (2016). Origem da palavra Londrix [mensagem pessoal] Mensagem recebida por <Facebook: Frederico Fernandes> em: 22 abr. 2016.

CAUQUELIN, Anne (2005). Arte contemporânea: uma introdução. Tradução de Rejane Janowitzer. São Paulo: Martins Fontes.

DEMARCHI, Ademir (Org.) (2014). 101 poetas paranaenses: antologia de escritas poéticas do século XIX-XXI: 1959-1993. Curitiba: Biblioteca Pública do Paraná. v. 2.

FERRAZ, Paulo (Org.) (2011). Roteiro da poesia brasileira: anos 90. São Paulo: Global.

FERREIRA, Antonio C.; SIMON, Cristiano G. B. (1988). Tensões da modernidade em Londrina. História: Questões e Debates, Curitiba, ano 9, n. 17, p. 334-59.

LEONE, Luciana di (2014). Poesia e escolhas afetivas: edição e escrita na poesia contemporânea. Rio de Janeiro: Rocco Digital. E-Reader.

MARQUES, Fabrício (Org.) (2013). A nova poesia brasileira. Suplemento Literário de Minas Gerais, Belo Horizonte, ed. especial, maio.

MENDONÇA, Maurício Arruda (1997). Eu caminhava assim tão distraído. Rio de Janeiro: 7 Letras.

MENDONÇA, Maurício Arruda (2002a). A sombra de um sorriso. Londrina: Atrito Art.

MENDONÇA, Maurício Arruda (2002b). Epigrafias. Jales: Ciência do Acidente.

MINARELLI, Enzo (2014). As razões da voz: entrevistas com protagonistas da poesia sonora no século XX. Tradução e organização de Frederico Fernandes. Londrina: Eduel.

RANCIÈRE, Jacques (2010). Estética e política: a partilha do sensível. Tradução de Vanessa Brito. Porto: Dafne.

SATO, Nenpuku (1999). Trilha forrada de folhas. Tradução e organização de Maurício Arruda Mendonça. São Paulo: Ciência do Acidente. 
STERZI, Eduardo (2002). Relíquia íntima e perecível. Sebastião: novos olhos sobre a nova poesia brasileira, n. 2, p. 88-97.

VASQUES, Marco (2010). Diálogos com a literatura brasileira. Porto Alegre: Movimento; Joinville: Letradágua. v. 3.

VIANNA, Christine (Org.) (2000). Antologia de poetas londrinenses 12. Londrina: Atrito Art.

VIANNA, Christine (Org.) (2016). Um dedo de prosa. Londrina: Atrito Art.

Recebido em 7 de novembro de 2016.

Aprovado em 8 de maio de 2017.

\section{resumo/abstract/resumen}

\section{O caso Londrix: subjetividade, territorialização e política na poesia de Maurício Arruda Mendonça}

Frederico Fernandes

O artigo trata da multiplicidade de papéis do poeta na literatura contemporânea e demonstra como as várias atividades desdobram-se numa função embreante, na qual vários produtos tendem a repetir o autor e sua obra. $\mathrm{O}$ poeta contemporâneo passa, dessa maneira, a agir sobre o mundo, utilizando a literatura, suas manifestações e expressões como um mecanismo de atuação política. $O$ artigo foca, como estudo de caso, na rede de poetas Londrix e, em específico, na análise da poesia de Maurício Arruda Mendonça, de modo a demonstrar como se articulam subjetividade, construção de um território e ação política.

Palavras-chave: subjetividade, territorialização, política, Londrix, Maurício Arruda Mendonça.

\section{The Londrix case: subjectivity, territorialization and politics in the poetry of Maurício Arruda Mendonça}

Frederico Fernandes

This article deals with the multiplicity of the poet's roles in contemporary literature and demonstrates how the various activities unfold in a clutch function, according to which different cultural products tend to repeat the author and his work. The contemporary poet acts on the world, using the literature, its manifestations and discourses, as a tool of political activity. The 
article focuses on Londrix poets and, in particular, on the Mauricio Arruda Mendonça's works in order to demonstrate how subjectivity, construction of a territory and political action are connected.

Keywords: subjectivity, territorialization, politics, Londrix, Maurício Arruda Mendonça.

\section{El caso Londrix: subjetividad, territorialización y política en la poesía de Maurício Arruda Mendonça}

Frederico Fernandes

El artículo versa sobre la multiplicidad de papeles del poeta en la literatura contemporánea y demuestra como las diferentes actividades se desdoblan en una función aglutinadora/catalizadora, en la que varios productos tienden a repetir al autor y su obra. El poeta contemporáneo pasa, de esta manera, a operar sobre el mundo, utilizando la literatura, sus manifestaciones y expresiones, como un mecanismo de actuación política. El artículo se centra, como estudio de caso, en la red de poetas Londrix y, en particular, en el análisis de la poesía de Maurício Arruda Mendonça, para demostrar cómo se articulan subjetividad, construcción de un territorio y acción política.

Palabras clave: subjetividad, territorialización, política, Londrix, Maurício Arruda Mendonça. 